\title{
The financial impact of improved hand hygiene on healthcare-associated infections in the UK
}

\author{
Katie-Rose Cawthorne', Jason Dean ${ }^{2}$, Richard PD Cooke', ${ }^{1}$ \\ 'Department of Innovation, Alder Hey Children's NHS Foundation Trust, Liverpool, England \\ 2Department of Finance, Alder Hey Children's NHS Foundation Trust, Liverpool, England \\ ${ }^{3}$ Department of Medical Microbiology, Alder Hey Children's NHS Foundation Trust, Liverpool, England
}

\section{Corresponding author:}

Katie-Rose Cawthorne, Department of Innovation, Alder Hey Children's NHS Foundation Trust, Liverpool, England Tel: +447989683865 | Email: katierosecawthorne@gmail.com

\begin{abstract}
Background: Though high hand hygiene $(\mathrm{HH})$ levels significantly reduce the risk of healthcare-associated infections (HCAls), the current cost of HCAls and the impact of optimal $\mathrm{HH}$ practices on HCAls are poorly defined. The last NHS England financial assessment was in 2009.

Methods: The number of HCAls per bed per year for NHS England were calculated and average costs were attributed using data from three sources; National Audit Office report, a commercially available calculator, and a financial analysis by a specialist paediatric hospital in England. Improved HH compliance for NHS England was based on a sustained rise in compliance rates from 50 to $80 \%$ combined with an HCAI reduction of at least $20 \%$. The cost savings based on such improvements were then calculated.
\end{abstract}

Results: In 2020, it is estimated that the number of HCAls per bed per year ranges from 3.0 to 9.3, with a midpoint of 5.1. The direct costs of HCAI to NHS England were found to lie between $£ 1.6$ and $£ 5$ billion. Based on a $20 \%$ reduction in $\mathrm{HCAI}$ rates, this could lead to cost savings of between $£ 322$ million and $£ 1$ billion per year.

Conclusion: Current direct costs of HCAls consume approximately $1.3 \%$ to $4.1 \%$ of NHS England's annual budget. Improving HH compliance among healthcare workers can lead to significant cost savings. There appears to be a strong financial argument for investment into innovative $\mathrm{HH}$ compliance technologies that have been historically perceived as too expensive.

\section{KEYWORDS}

Healthcare-associated infections; hand hygiene; financial analysis

\section{INTRODUCTION}

Healthcare-associated infections (HCAIs) caused by methicillin-resistant Staphylococcus aureus (MRSA) and Clostridioides difficile (C.difficile) directly contributed to 9,000 deaths in the National Health Service (NHS) in 2007 [1]. In Canada, more recent data from 2013 shows that HCAls were responsible for 8,000 deaths in 2013 [2]. More than 50\% of HCAls are considered to be preventable [3]. Hence, as every healthcare system has finite resources, it is vital to understand the financial implications of HCAls in order to adequately allocate resources for prevention and intervention. Investment in combating HCAls means that resources will be redirected away from other competing healthcare needs. It is therefore essential that economic arguments are clearly put forward.

A financial review of HCAls in NHS England has not been published since 2009 [4]. The last national HCAI prevalence study in 2011 for NHS England found a prevalence of $6.4 \%$, comparable to an earlier figure of $8.2 \%$ in 2006 [5]. It is

Funding: This research did not receive any specific grant from funding agencies in the public, commercial, or not-for-profit sectors.

Conflict of interest: RPDC reports personal fees from Hand Hygiene Solutions Limited, outside the submitted work. 
therefore likely that the prevalence of HCAls was within this range when the National Audit Office (NAO) report was published in 2009. It is, however, reasonable to assume that $\mathrm{HCAl}$ costs have risen. In 2009, these costs were found to be over $£ 1$ billion a year for NHS England [4]. For comparison, a similar US review in the same year suggested HCAI costs of between $\$ 28$ billion and \$45 billion per year [6].

Though good $\mathrm{HH}$ compliance is one of the most influential factors in preventing $\mathrm{HCAls}$, its quantitative contribution to $\mathrm{HCAl}$ reduction has been poorly described [7]. HH compliance in the healthcare environment is an ongoing challenge for Infection Prevention and Control (IPC) teams, with monitoring of staff compliance being time consuming, labour intensive and methodologically flawed [8]. Innovative technologies to improve $\mathrm{HH}$ compliance could be the key to prevent at least some HCAls. However, without a clear understanding of the costs of HCAls, it is impossible to make an economic argument to invest in such technologies. We, therefore, present an analysis of the current financial impact of HCAls in NHS England and assess the financial significance of sustained improved hand hygiene compliance rates on HCAI reduction.

\section{METHODS}

\section{HCAls per bed per year}

The number of acute non-specialist and specialist trusts in NHS England were identified from data held by the NHS Confederation [9]. The current number of general acute hospital beds in NHS England was obtained from the latest report by the Kings Fund [10]. The average number of general acute hospital beds per trust was then determined.

The average annual number of HCAls per hospital bed per year was determined from a number of sources; the NAO report from 2009 [4], a commercially available calculator 'Surewash' [11], and NHS Digital data from 2018-2019 [12]. Data was retrieved from the commercially available calculator in 2018 prior to being archived on the provider's website. Using NHS digital data, HCAls per bed per year were estimated by comparing Finished Admission Episodes (FAE) [12] with the most current HCAI prevalence reports from Europe [13], England [5] and Scotland [14]. FAEs are periods of inpatient care under one consultant in one provider [12].

For the purpose of this study, HCAls were defined according to the protocol used by the Health Protection Agency in the most recent survey of inpatients in England [5].

The term HCAl covers a wide range of infections. The most well-known include those caused by MRSA, C.difficile and Escherichia coli. Though key data are not available for all HCAls, the five with the highest impact on healthcare systems are considered to be surgical site infections (SSIs), central lineassociated bloodstream infections (CLABSIs), catheter-associated urinary tract infections (CAUTIs), ventilator-associated pneumonia and C.difficile infection (CDI) [3]. These types of HCAls are the ones considered in this financial analysis.

The annual average number of HCAls per bed were calculated both at an individual trust level and for NHS England as a whole.

\section{Financial cost of HCAIs}

The annual financial burden of HCAl costs to NHS England was determined by calculating and then combining three key variables: the average cost of an $\mathrm{HCAl}$, the annual number of HCAls per bed for a hospital trust and the average number of total hospital beds for an NHS trust.

Average cost of an $\mathrm{HCAl}$ was estimated from three independent and valid sources; the NAO report [4], a commercially available calculator 'Surewash' based on US HCAI data [11] and a local calculation of average HCAI cost, undertaken by Alder Hey Children's NHS Foundation Trust finance department (AHFT), following national costing guidance.

Variables considered in the NAO costings were nursing care, hospital overheads, medical time, investigations, consumables, and drugs [15]. The commercially available calculator used an algorithm not visible to the end user [11]. The AHFT cost calculation used the national Patient Level and Costing System (PCLIS) methodology [16]. This included an average increased length of hospital stay of at least seven days to determine the minimum average HCAI cost. NHS England has previously stated that inpatient stay may be extended by at least eight days as a result of an HCAI [17]. To illustrate individual HCAI costs, using a Patient Level Information and Costing System (PLICS), AHFT also calculated the financial cost of two specific HCAls based on 2019/20 surveillance data submitted to Public Health England: CLABSIs due to $S$. aureus and CDIs. AHFT did this by extracting the actual costs of each individual patient from the trust's local PLICS database.

Average annual cost of HCAls per trust were calculated by combining the average cost of an $\mathrm{HCAl}$ with the average number of HCAls per bed per year and the average number of beds per trust.

Annual HCAI costs for NHS England were determined by combining the average cost of an HCAl with the number of HCAls per bed per year and the total number of beds within NHS England.

\section{Impact of sustained $\mathrm{HH}$ compliance improvement on HCAI rates.}

For the purposes of financial modelling, current $\mathrm{HH}$ compliance rates in NHS England were assumed to be $50 \%$ at best, if assessed by independent auditors [18]. A realistic and sustainable improvement goal was set at $80 \% \mathrm{HH}$ compliance. This was based on a Swiss multicentre analysis published in 2017 [19].

A recent report suggests that for every $10 \%$ improvement in $\mathrm{HH}$ compliance, this correlates with a $6 \%$ reduction in $\mathrm{HCAI}$ rates [7]. An historical review from 1995 estimated that good $\mathrm{HH}$ compliance $(63-90 \%)$ can lead to at least a $50 \%$ reduction in HCAls [20]. With all these sources considered, this financial model assumes that improving $\mathrm{HH}$ compliance from $50 \%$ to $80 \%$ leads to at least a $20 \%$ overall reduction in rates of $\mathrm{HCAl}$.

The average annual costs of HCAls to an individual trust and to NHS England were used to establish cost savings when there is a $20 \%$ reduction in $\mathrm{HCAl}$ rate. 


\section{RESULTS}

Number of beds in an NHS England hospital

Within NHS England, there are currently 135 acute non-specialist trusts and 17 acute specialist trusts giving a total of 152 acute trusts [9]. For 2019-20, NHS England had 101, 255 general and acute beds [10]. Bed occupancy for 2019/20 was estimated to be $90.2 \%$. However, the true level of hospital bed use was even higher than this figure as it regularly exceeds 95\% in winter [10]. For the purposes of the financial analysis, the average number of beds per acute trust was estimated at $666(101,255 / 152)$.

\section{Average number of HCAls per bed per year}

The average number of HCAls per NHS England general/ acute bed per year was estimated from a variety of sources. The 2009 NAO report estimated that there were at least 300,000 HCAls per year [4]. If it is assumed that in 2020 the HCAI number remains unchanged, the average annual number of HCAls per trust would be 1,974 (300,000/152). In 2009, the figure for total general and acute beds in NHS England was 122,538, which would indicate that the number of annual HCAls per bed in 2009 was 2.4 $(300,000 / 122,538)$. If it is assumed that the overall number of HCAls per year has not altered significantly since the NAO report, this figure would rise to $3.0(300,000 / 101,255)$ in 2020.

Based on a hospital with 666 beds, the commercially available calculator [11] estimated 3,386 HCAls per year. This gives an annual per bed HCAI rate of $5.1(3,386 / 666)$.
For 2018/19, NHS Digital identified 17.1 million FAEs [12]. HCAI prevalence rates from Europe [13] and England [5] in 2011, and Scotland in 2016 [14] were 5.7\%, 6.4\% and 4.5\% respectively. Assuming the current $\mathrm{HCAI}$ prevalence in NHS England is an average of these rates (5.5\%), the number of HCAls per year was estimated to be 940,500 (5.5\% of $17.1 \mathrm{~m}$ ) for NHS England. This equates to 9.3 HCAls per bed per year $(940,500 / 101,255)$.

The average number of HCAls per bed per year in NHS England may be in the range of 3.0 to 9.3 .

\section{Financial cost of HCAls}

Using the NAO report, the cost of each HCAI was approximately $£ 3,333$ ( $£ 1$ billion/300,000) at that time [4]. Assuming an average annual inflation rate of $2 \%$ between 2009 and 2020, this figure would rise to $£ 4,125$ per HCAI.

The commercially available calculator produced a cost of US\$ 25 million for 3,386 HCAls (US\$ 7,383 per HCAI or £5,687 per $\mathrm{HCAl}$ ) [11].

AHFT average costs were similar at $£ 5,300$ per HCAI. The average $\mathrm{HCAl}$ costs for CLABSIs and $\mathrm{CDI}$ at $\mathrm{AH}$ were approximately $£ 27,000$ and $£ 8,600$ respectively. For the purposes of the economic calculation $£ 5,300$ was chosen as the average cost of an HCAI due to being a mid-scale figure. The average direct costs for HCAI per trust and for NHS England are shown in Table 1.

Impact of improved $\mathrm{HH}$ compliance on $\mathrm{HCAl}$ costs per bed Assuming that $\mathrm{HH}$ compliance is improved from $50 \%$ to $80 \%$, HCAI rates would see a $20 \%$ reduction. Table 2 shows the average

TABLE 1: Average direct costs for HCAI per trust and for NHS England as a whole, using a range of HCAls per bed. Average cost of an HCAl is $£ 5,300$.

\begin{tabular}{|l|l|l|l|}
\hline $\begin{array}{c}\text { HCAls per bed } \\
\text { per year }\end{array}$ & \multicolumn{1}{|c|}{$\begin{array}{c}\text { HCAls per average } \\
\text { 666-bed trust per year }\end{array}$} & $\begin{array}{c}\text { Average annual HCAI } \\
\text { cost per trust per year }(\boldsymbol{\xi})^{*}\end{array}$ & $\begin{array}{c}\text { Average annual HCAI cost } \\
\text { for NHS England per year }(\boldsymbol{(})^{* *}\end{array}$ \\
\hline 3.0 & 1,998 & 10.6 million & $1.6(\mathrm{CA} \$ 2.7)$ billion \\
\hline 5.1 & 3,397 & 18.0 million & $2.7(\mathrm{CA} \$ 4.6)$ billion \\
\hline 9.3 & 6,194 & 32.8 million & $5.0(\mathrm{CA} \$ 8.5)$ billion \\
\hline
\end{tabular}

* Number of beds in an average trust is 666 .

**Number of beds in NHS England in 2020 is 101,255.

TABLE 2: Average cost saving per trust and for NHS England when hand hygiene compliance is $\mathbf{8 0} \%$, leading to a $\mathbf{2 0} \%$ reduction in HCAl. Table provides estimates using a range of HCAls per bed. Average cost of an HCAl is $£ 5,300$.

\begin{tabular}{|l|l|l|l|l|}
\hline $\begin{array}{l}\text { HCAls per bed } \\
\text { per year with } \mathbf{5 0} \% \\
\text { HH compliance }\end{array}$ & $\begin{array}{l}\text { HCAls per bed } \\
\text { per year with } \mathbf{8 0} \% \\
\text { HH compliance }\end{array}$ & $\begin{array}{l}\text { Difference in } \\
\text { HCAls per bed } \\
\text { per year from } \\
\mathbf{5 0} \text { to } \mathbf{8 0} \% \mathbf{H H} \\
\text { compliance }\end{array}$ & $\begin{array}{l}\text { Average annual } \\
\text { cost saving per } \\
\text { trust per year }(\boldsymbol{E}) *\end{array}$ & $\begin{array}{l}\text { Average annual cost saving } \\
\text { for NHS England per year }(\boldsymbol{E}) * *\end{array}$ \\
\hline 3.0 & 2.4 & 0.6 & 2.1 million & $322(\mathrm{CA} \$ 564)$ million \\
\hline 5.1 & 4.1 & 1 & 3.5 million & $537(\mathrm{CA} \$ 912)$ million \\
\hline 9.3 & 7.4 & 1.9 & 6.7 million & $1.0(\mathrm{CA} \$ 1.7)$ billion \\
\hline
\end{tabular}

*Number of beds in an average trust is 666 .

**Number of beds in NHS England in 2020 is 101,255. 
annual cost saving for a trust and for NHS England as a whole with improved $\mathrm{HH}$ compliance.

\section{DISCUSSION}

Our analysis found that the total annual cost of HCAI to NHS England in 2020 is likely between $£ 1.6$ billion and $£ 5$ billion. Total NHS England commissioning budget for 2019/20 was $£ 121$ billion, thus the cost of HCAI represents roughly $1.3 \%$ to $4.1 \%$ of the total budget [21]. For context and comparison, the total budget allocated to General Practice in the same period was $£ 8.8$ billion (7.2\% of total budget) [21].

The costs we identified are deliberately prudent and are likely an underestimate of the real costs to NHS England. For example, the number of HCAls (300,000 annually) was originally reported in 2000, which, at the time, was highlighted to be conservative [22]. Graves et al. reported that HCAl costs have a tendency to be overestimated, which can be problematic when cost savings are not realized following implementation of IPC interventions [23]. It is therefore better to underestimate costs, rather than overestimate, so resources are not unintentionally directed away from other areas within the health economy.

Our analysis provides a proposal for the current financial burden of HCAls in NHS England. With relevant financial costs for 2020, a strategy for reducing this burden must be explored. The first step is to break down which HCAls contribute most to this cost. A study by Zimlichman et al demonstrated that surgical site infections (SSIs) contribute most (33.7\%) to the overall frequency and cost of HCAls, although these types of infections are not well tracked due to their diversity, use of day surgery, early discharge of patients, combined with lack of coordinated follow up [3]. However, from an HCAl cost-per-case basis, CLABSIs are the most costly HCAls. Our analysis confirms this. The average CLABSI costs $£ 27,000$, which is five times higher than the average HCAI cost used in this analysis. CLABSIs due to S.aureus and CDIs are arguably the most well tracked as they are included in the Public Health England mandatory reporting scheme for acute trusts. Currently these avoidable costs are simply incorporated into trusts' ongoing revenue costs. Using our proposed financial model, healthcare organizations can attribute costs to their HCAl data, allowing clearer sight of this significant financial burden. In the UK, PLICS has recently replaced reference costs as the official NHS cost collection methodology. The PLICS portal gives hospital trusts the ability to analyze and compare their own costs against those of all healthcare providers [16].

Though there are many factors that may reduce HCAls, effective $\mathrm{HH}$ is considered the most important way to prevent pathogen transmission in healthcare settings. However, maintaining high levels of $\mathrm{HH}$ compliance remains challenging and is often difficult to measure.

Our financial model of sustained $\mathrm{HH}$ compliance linked to $\mathrm{HCAl}$ reduction was based on a prolonged rise in compliance rates from $50 \%$ to $80 \%$ associated with a $\mathrm{HCAl}$ reduction rate of at least $20 \%$. Though demanding, we believe that such targets are achievable. Using a multimodal strategy to improve and sustain $\mathrm{HH}$ compliance, Staines et al. were able to achieve an improvement from $61.9 \%$ to $88.3 \%$ over 18 months across five participating hospitals, which was sustained at 88.9\% 12 months after the intervention concluded [19]. Furthermore, Sickbert-Bennett et al. have demonstrated that an improvement in $\mathrm{HH}$ compliance from a high baseline level $(>80 \%)$ to an even higher level (>95\%) can lead to further hospital-wide decreases in HCAls [7].

Innovative $\mathrm{HH}$ monitoring technologies have been developed to improve surveillance of $\mathrm{HH}$ compliance with a goal to reduce $\mathrm{HCAl}$ rates. A reduction in HCAls, specifically CDI [24], CAUTI and CLABSI [25] and MRSA infection [26], has been reported with the introduction of an automated $\mathrm{HH}$ monitoring system (AHHMS) when combined with an organization's existing HH campaign strategy. However, simply introducing an AHHMS is not a panacea for hand hygiene improvement. Nevertheless, they do provide robust data, which can be used to drive improvements in patient safety if coupled with effective interventions to affect behaviour change. Such a multimodal strategy should include complementary activities such as goal setting, reward incentives and accountability [27].

A targeted MRSA focused $\mathrm{HH}$ campaign demonstrated cost savings of $\$ 1.2$ million and $\$ 2.5$ million Canadian ( $£ 699,000-£ 1.45$ million) annually at the hospital level [28]. Developing this further, our analysis showed that when there is a $20 \%$ reduction of all types of HCAls, this can lead to savings in the region of $£ 2.1$ million to $£ 6.7$ million for each hospital trust. Though $\mathrm{HH}$ monitoring systems are perceived as costly, there does appear to be a strong financial argument for their implementation. Our commercial review of such systems shows that prices range from $\$ 460-650$ ( $£ 365$ - 527) per bed per year [29], or $£ 243,000$ to $£ 351,000$ per 666 bed trust. Providing their ability to sustain a reduction in HCAls is well evidenced it makes economic sense to invest in such technologies.

Our study has some limitations. Concerns have been raised about the validity of previously applied methods used to determine the cost of an HCAI [23]. Our financial model has therefore been deliberately cautious, potentially causing our cost estimates to be overly conservative. Similarly, though the World Health Organisation estimates that $\mathrm{HH}$ could reduce HCAls by between 30 to $70 \%$ [30], our model has been set at the very low end of the range. This may result in an underestimate of the cost savings involved. National HCAI prevalence studies occur infrequently. The current HCAI prevalence within NHS England is not known, though we have tried to address this point by pooling the results of three relevant prevalence reports. There is not a comprehensive national HCAI surveillance programme in NHS England to capture the prevalence and costs of all five key HCAls considered in this study. In the US, SSIs and CDI have been estimated to be the most frequent HCAls nationwide, with SSIs contributing most to overall costs (33.7\% of the total) [3]. Though few studies have examined the total economic burden of SSIs, one from the UK estimated the mean additional cost attributable to SSIs at $£ 5,239$ [31]. Our economic calculation 
of an average $\mathrm{HCAl}$ cost at $£ 5,300$ may again suggest that our financial estimate may be conservative.

In summary, our analysis provides an up-to-date financial model for healthcare organizations to estimate the local financial burden from HCAls. The quality of published economic evaluations on HCAl interventions is, at best, moderate [28]. Ongoing research is therefore needed to assist IPC teams in making evidence-based decisions on which HCAI prevention strategies to invest in.

\section{REFERENCES}

1. Office for National Statistics. (2008). Health Statistics Quarterly: No. 39 Autumn 2008. Retrieved from: https:// webarchive.nationalarchives.gov.uk/20151014023532/ http://www.ons.gov.uk/ons/rel/hsq/health-statisticsquarterly/no--39--autumn-2008/index.html

2. Public Health Agency of Canada. (2013). The Chief Public Health Officer's Report on the State of Public Health in Canada 2013 - Infectious disease - The never-ending threat - Canada.ca. Retrieved from: https://www.canada. ca/en/public-health/corporate/publications/chief-publichealth-officer-reports-state-public-health-canada/ chief-public-health-officer-report-on-state-public-healthcanada-2013-infectious-disease-never-ending-threat.html

3. Zimlichman, E., Henderson, D., Tamir, O., Franz, C., Song, P., Yamin, C. K., Bates, D. W. (2013). Health care-associated infections. A meta-analysis of costs and financial impact on the US healthcare system. JAMA Internal Medicine, 173(22), 2039. https://doi.org/10.1001/ jamainternmed.2013.9763

4. National Audit Office. (2009). Reducing Healthcare Associated Infections in Hospitals in England. Retrieved from: https://www.nao.org.uk/wp-content/ uploads/2009/06/0809560.pdf

5. Health Protection Agency. (2012). English National Point Prevalence Survey on Healthcare-associated Infections and Antimicrobial Use: 2011 data. Retrieved from: https://webarchive.nationalarchives.gov. uk/20140714091616/http://www.hpa.org.uk/Topics/ InfectiousDiseases/InfectionsAZ/AntimicrobialResistance/ HCAIPointPrevalenceSurvey/

6. Stone, P. W. (2009). Economic burden of healthcareassociated infections: an American perspective. Expert Review of Pharmacoeconomics \& Outcomes Research, 9(5), 417-422. https://doi.org/10.1586/erp.09.53

7. Sickbert-Bennett, E. E., DiBiase, L. M., Willis, T. M. S., Wolak, E. S., Weber, D. J., \& Rutala, W. A. (2016). Reduction of healthcare-associated infections by exceeding high compliance with hand hygiene practices. Emerging Infectious Diseases, 22(9), 1628-1630. https:// doi.org/10.3201/eid2209.151440

8. Jeanes, A., Coen, P. G., Gould, D. J., \& Drey, N. S. (2019). Validity of hand hygiene compliance measurement by observation: A systematic review. American Journal of Infection Control, 47(3), 313-322. https://doi. org/10.1016/j.ajic.2018.08.004
9. NHS Confederation. (2017). NHS statistics, facts and figures. Retrieved from: https://www.nhsconfed.org/ resources/key-statistics-on-the-nhs

10. The Kings Fund. (2020). NHS hospital bed numbers: past, present, future. Retrieved from: https://www.kingsfund. org.uk/publications/nhs-hospital-bed-numbers

11. Surewash. (n.d.). Retrieved from: https://surewash.com/js/ calculator.js

12. NHS Digital. (2019). Hospital admitted patient care and adult critical care activity 2018-19. Retrieved from: https:// files.digital.nhs.uk/F2/E70669/hosp-epis-stat-admi-summrep-2018-19-rep.pdf

13. European Centre for Disease Prevention and Control. (2013). Point prevalence survey of healthcare-associated infections and antimicrobial use in European acute care hospitals 2011-2012. Retrieved from: https://www.ecdc. europa.eu/en/publications-data/point-prevalence-surveyhealthcare-associated-infections-and-antimicrobial-use-0

14. Health Protection Scotland. (2017). National point prevalence survey of healthcare associated infection and antimicrobial prescribing 2016. Retrieved from: https:/hpspubsrepo.blob.core.windows.net/hpswebsite/nss/2204/documents/1_PPS\%20National\%20 Report\%202016.pdf

15. Public Health Laboratory Services. (1999). The socioeconomic burden of hospital acquired infection. Retrieved from:https://webarchive.nationalarchives. gov.uk/20120510093318/http://www.dh.gov.uk/prod_ consum_dh/groups/dh_digitalassets/@dh/@en/documents/ digitalasset/dh_4089725.pdf

16. Brown, S. (2020, March). Costing: patient progress. Healthcare Finance Management Association.

17. NHS England. (2016). GE3 hand hygiene technology. Retrieved from: https://www.england.nhs.uk/wp-content/ uploads/2016/03/ge3-hand-hygien-tchnlgy.pdf

18. Pan, S.-C., Tien, K.-L., Hung, I.-C., Lin, Y.-J., Sheng, W.-H., Wang, M.-J., Chen, Y.-C. (2013). Compliance of health care workers with hand hygiene practices: Independent advantages of overt and covert observers. PLoS ONE, 8(1), e53746. https://doi.org/10.1371/journal. pone. 0053746

19. Staines, A., Amherdt, I., Lécureux, E., Petignat, C., Eggimann, P., Schwab, M., \& Pittet, D. (2017). Hand hygiene improvement and sustainability: assessing a breakthrough collaborative in western Switzerland. Infection Control Hospital Epidemiology, 38(12), 1420-1427. https://doi.org/10.1017/ice.2017.180

20. Larson, E., \& Kretzer, E. K. (1995). Compliance with handwashing and barrier precautions. Journal of Hospital Infection, 30, 88-106. https://doi.org/10.1016/01956701(95)90010-1

21. NHS England and NHS Improvement. (2019). NHS England and NHS Improvement Funding and Resource 2019/20: Supporting 'The NHS Long Term Plan.' Retrieved from: https://www.england.nhs.uk/wp-content/ 
uploads/2019/03/nhse-mhsi-funding-and-resource-2019-20supporting-nhs-ltp.pdf

22. House of Commons. (2005). Twenty-fourth report: Improving patient care by reducing the risk of hospital acquired infection: A progress report (HC 544). Retrieved from: https://publications.parliament.uk/pa/cm200405/cmselect/ cmpubacc/554/55402.htm

23. Graves, N., Harbarth, S., Beyersmann, J., Barnett, A., Halton, K., \& Cooper, B. (2010). Estimating the cost of health care associated infections: Mind your p's and q's. Clinical Infectious Diseases, 50(7), 1017-1021. https://doi.org/10.1086/651110

24. Knepper BC, Amber MM, Young HL. (2020). Impact of an automated hand hygiene monitoring system combined with a performance improvement intervention on hospital-acquired infections. Infection Control Hospital Epidemiology, 931-937.. https://doi.10.1017/ice.2020.182

25. McCalla S, Reilly M, Thomas R, McSpedon d, McMahon LA, Palumbo M.(2018) An automated hand hygiene compliance system is associated with decreased rates of healthcareassociated infections. American Journal of Infection Control, 46, 1381-1386.

26. Kelly JW, Blackhurst d, McAtee W, Steed C. (2016). Electronic hand hygiene monitoring as a tool for reducing health care -associated methicillin resistant Staphylococcus aureus infection. American Journal of Infection Control, 44, 956-957.
27. Boyce JM, Laughman JA, Ader MH, Wagner PT, Parker AE, Arbogast JW. (2019). Impact of an automated hand hygiene monitoring system and additional promotional activities on hand hygiene performance rates and healthcare-associated infections. Infection Control Hospital Epidemiology, 40, 741-747.https://doi:10.1017/ice.2019.77

28. Tchouaket Nguemeleu, E., Beogo, I., Sia, D., Kilpatrick, K., Séguin, C., Baillot, A., Boivin, S. (2020). Economic analysis of healthcare-associated infection prevention and control interventions in medical and surgical units: Systematic review using a discounting approach. Journal of Hospital Infection, 106,134-154.. https://doi.org/10.1016/j. jhin.2020.07.004

29. Cooke, R., \& Corke, C. (2019). A review of automated hand hygiene monitoring systems-why is uptake so poor? Journal of Infection Prevention, 20(32).

30. World Health Organisation. WHO guidelines on hand hygiene in health care, first global safety challenge clean care is safer care. (2009). Retreived from: https://apps.who. int/iris/bitstream/handle/10665/44102/9789241597906eng.pdf

31. Jenks PJ, Laurent M, McQuarry S, Watkins R. (2014). Clinical and economic burden of surgical site infection (SSIO and predicted financial consequences of elimination of SSI from an English hospital. Journal of Hospital Infection, 86, 24-33. 